\title{
Are Mineral Toppings of Asphalt Roofing Sufficient to Protect Flat Roofs and Roofing Felt Alone?
}

\author{
Tomasz Szkuta $^{1}$ and Maria Wesołowska ${ }^{2}$ \\ ${ }^{1}$ Polish Association of Civil Engineers and Technicians (PZITB) Branch in Torun, \\ Szeroka 34 Str., 87-100 Toruń, Poland, tomszkuta@gmail.com \\ ${ }^{2}$ University of Technology and Life Sciences in Bydgoszcz, \\ Al. Prof. S. Kaliskiego 7, 85-796 Bydgoszcz, Poland, Wesolowska.Maria@utp.edu.pl
}

\begin{abstract}
Mineral surfaces are an integral part of bituminous roofing felt. Their task is to protect less resistant elements from the destructive effects of the environment. Since the first application in 1897, they have been constantly improved in the direction of better functionality and aesthetics. It often turns out that the intended effect has not been achieved. During the first years of operation, there are signs of roof damages on most facilities. Due to the complex interaction of roofing elements, several causes of damages can be defined. A group of processes taking place in mineral roofing toppings is important for roofing felt. Mineral surfaces are exposed to physical, chemical and biological factors. They cause losses due to the unavoidable breaking of adhesion to the modified asphalt. Pulling out caused by factors occurring on the roof is a long-term process with more effects on the covering, in particular its durability and tightness. In the paper, the reasons for the release of mineral topping from the SBS modified asphalt layer were defined. The analysis shows that as a result of significant degradation and harmful impact of mineral coverage, this layer may lose the ability to protect the roofing paper, and long-term changes threaten the durability of roofing materials. Solutions have been proposed to significantly reduce the phenomenon caused by specific factors.
\end{abstract}

Keywords: Mineral-Surfaced Tar Board, Durability of Roofing Felt, Impact of Environment.

\section{Introduction}

The subject of the work is the problem of top covering roofing felt. It is visible already in the first years of operation of the roofing felt. Depending on the quality of the roofing felt (price), this process takes place faster or slower, but inevitably occurs.
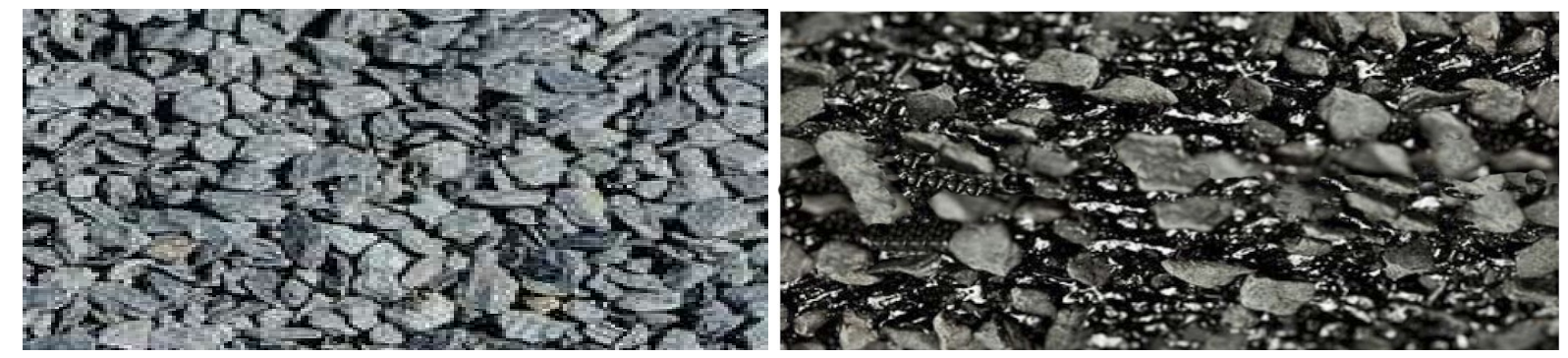

Figure.1 This is a comparison of mineral topping on new roofing paper and topping on the same roofing paper after several years of use in adverse conditions (on the right photo a drastic example of a significant loss of granules and exposure of asphalt in a roof depression - a periodic puddle). 


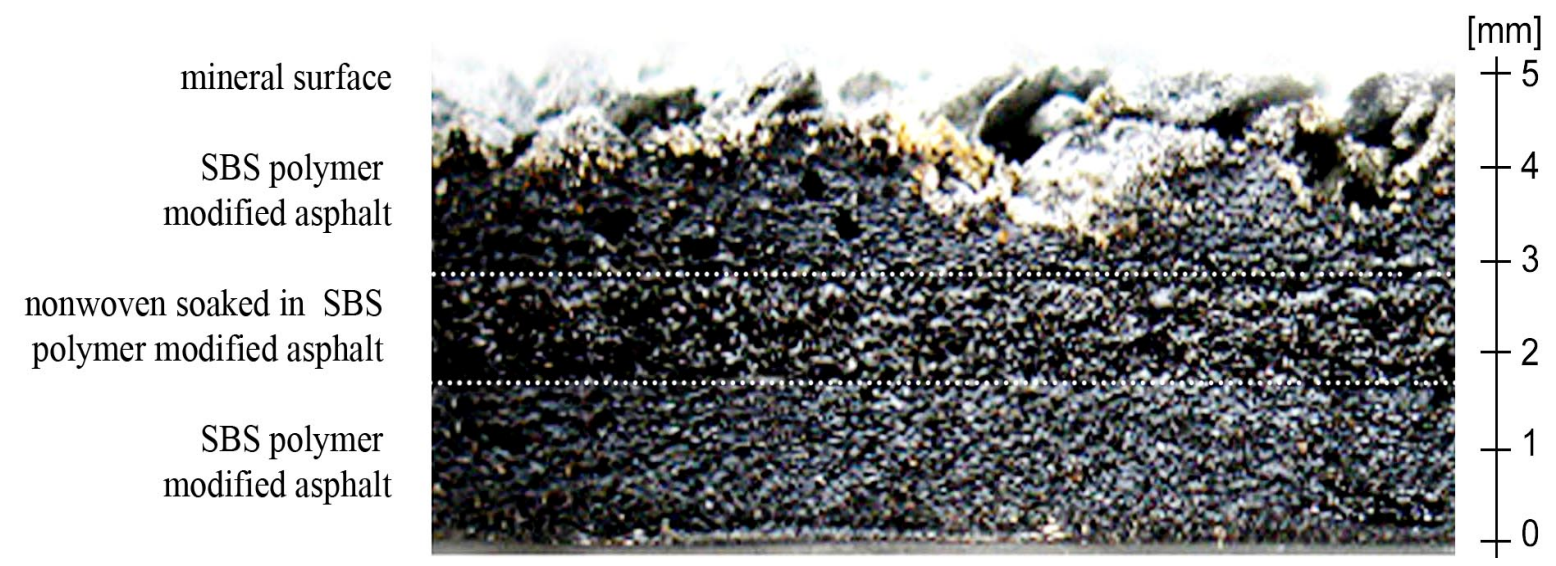

Figure 2. This is the cross-section of an ordinary polymer-asphalt covering roofing felt,

on polyester nonwovens using typical roofing felt.

Mineral surfaces protect the roof against atmospheric influences and to some extent against mechanical influences. They have been known, used, modified and improved for years. They are getting better and prettier really. They are absolutely necessary but do they fully fulfill their role on flat roofs? They were invented and began to be used a hundred years ago. Is the inertia of the solution justified and does it have to be continued?

Despite the objections of producers and some specialists outraged by such a suggestion,

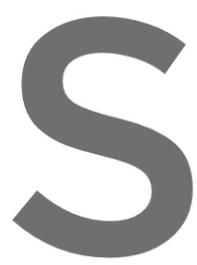
it must be made. Miner a cheap and quick solu cooperation with roofing felt and no cover in the light of the changes that are taking pla up to almost $90^{\circ} \mathrm{C}$ is an examined fact.
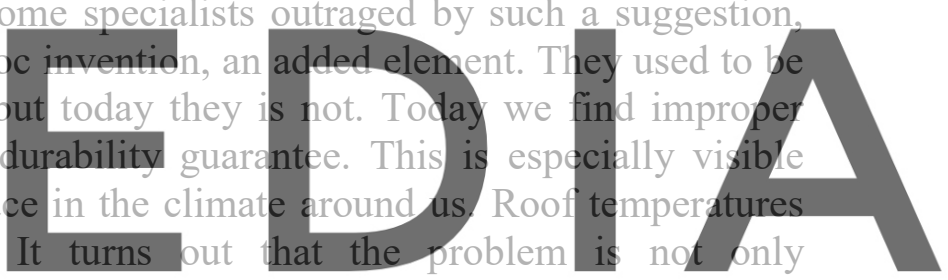

the temperature, there are many more.

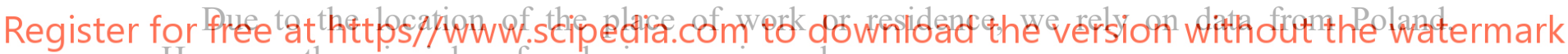
However, the principles of analysis are universal.

Roofing granules are released during the operation of roofs covered with roofing felt from polymer-modified asphalt (mainly SBS in Poland). The applicable European standard EN12039 from July 2016. regarding possible defects on up to $30 \%$ of the mineral topping, during tests, is significant. Such large roof defects are real, as shown in the above photos. The defect itself is one thing but the effects of the way they are formed are a much broader topic.

The purpose of the work is to analyze the reasons for the deterioration of roofing materials over time. Due to the possible volume of occurrence content, limited only to roofing granules.

Analyzes of other elements of cover materials on flat roofs should be expected in subsequent publications.

\section{Method}

To find out the reasons for the appearance of roofing defects and the effects on the roofing felt and roofs, an analysis of processes and phenomena occurring on the roofs is needed. For the purposes of the study, the processes were divided into groups depending on the seasons. 
General description of processes, impact on roofs (roof granules):

Autumn, winter, spring: snow retention; melting and freezing of snow in contact with the covering surface and stands (!), deepening effect (increased hydrostatic pressure), penetration into asphalt cracks and between granules and disintegration; the bottom layer of thawed and frozen snow turns into ice, the top layer from thawed snow (sun) and frozen turns into ice, after freezing it in whole we have a thick layer of ice with a significant mechanical breaking strength (linear expansion of the ice when the temperature drops below $0^{\circ} \mathrm{C}$ ) ; passing through $" 0^{\circ} \mathrm{C}$ " up to 100 times per year (deepening effects).

Summer: rainfall on a hot roof (hydrophobization is less effective - Table 1, significant energy of falling drops - Figure 4), soaking of mineral topping; rapid temperature changes, water, hail falling on the roof heated to almost $90^{\circ} \mathrm{C}$; chemical impact on toppings decomposition, leaching, formation of chemical solutions; leaching of soluble components of roofing felt (e.g. sulfur), solutions effecting on roof granules and other cover elements; crystallization of water chemical contaminations in crevices and soaked granules, destruction of granule-asphalt adhesion and cohesion of granules, increasing the concentration of solutions at subsequent precipitation; wet and dry deposition of media enabling the development of living organisms (lichen, algae, other).

Regardless of the season: linear expansion of roof materials and their interactions affecting mineral toppings; additional impact, wind pressure and suction transporting loose material; capillary penetration into granules, theoretically reduced by hydrophobization, practically depends on temperature (Figure 3), water politution (e.g. PH Tablet) and other phenomena associated with the shape and number of ppen pores may also occur.
Identification of the nuain physical phenomena generating the ndicated processes:
Weather conditions and their changes together with climate changes: precipitation; hunidity;
winds; insolation; tentperature changes; wet and dry deposition of mineral, chentical, organic and inorganic compounds and substances.

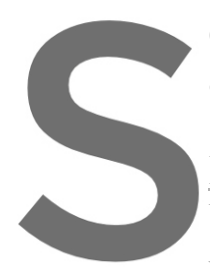

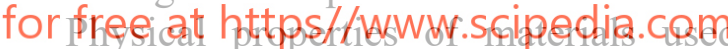

and their interactions: linear expansion (discontinuous linear expansion); adhesion and cohesion; humidity; solubility; hygroscopicity; surface tension; changes in physical state; density; melting and softening point; copolymer uncoupling temperature; viscosity stiffness; ductility; flexibility; thermal conductivity; brittleness; reflection; radiation absorption.

Chemical properties of materials used for covering, precipitation and deposits, and their interactions (as additional): $\mathrm{PH}$; causing chemical corrosion; change in physical properties (e.g. surface tension).

Research and analysis carried out:

We focused primarily on long-term observations and research of flat roofs in situ. An important observation during the tests turned out to be the quality of roofing, often correlated with the quality of the materials used. It should be emphasized here, that perfectly made covers made of the best materials on the market are not often the subject of expertise. They are much less frequently and more slowly damaged and constitute a small part of the market. We focused on the greater part of the market where the important measure of the quality of materials used and the quality of workmanship is the criterion of a lower price. 
Analysis of the impact of differences in linear expansion of polymer-asphalt layers reinforced with polyester nonwovens and mineral topping immersed in puddles formed in an improperly shaped roof surface: expansion of polymer-asphalt felt; ice expansion; thermal shock with rapid temperature changes (summer downpours, hail).

Analysis of the effect of crystallization of chemical compounds found in puddles on roofs: chemical compounds found on roofs; crystallization of chemical compounds between the granules; crystallization of chemical compounds in the joints of roofing felt sheets.

Analysis of weakening of roof paper sheets joints by the presence of granules embedded in joints in the context of linear expansion and crystallization in puddles: quality of joints and the way they are made; facilitating the possibility of water getting into the contacts areas; blasting through ice, the effect of temperature shrinkage of roofing felt.

Analysis of the impact of hydrophobization on the number of granules defects in real conditions on roofs: phenomena eliminating increased surface tension on hydrophobized materials (Table 1, Figure 3, Figure 4, Table 2), surfactants, the occurrence of these phenomena on roofs, the impact of these phenomena on defects of granules

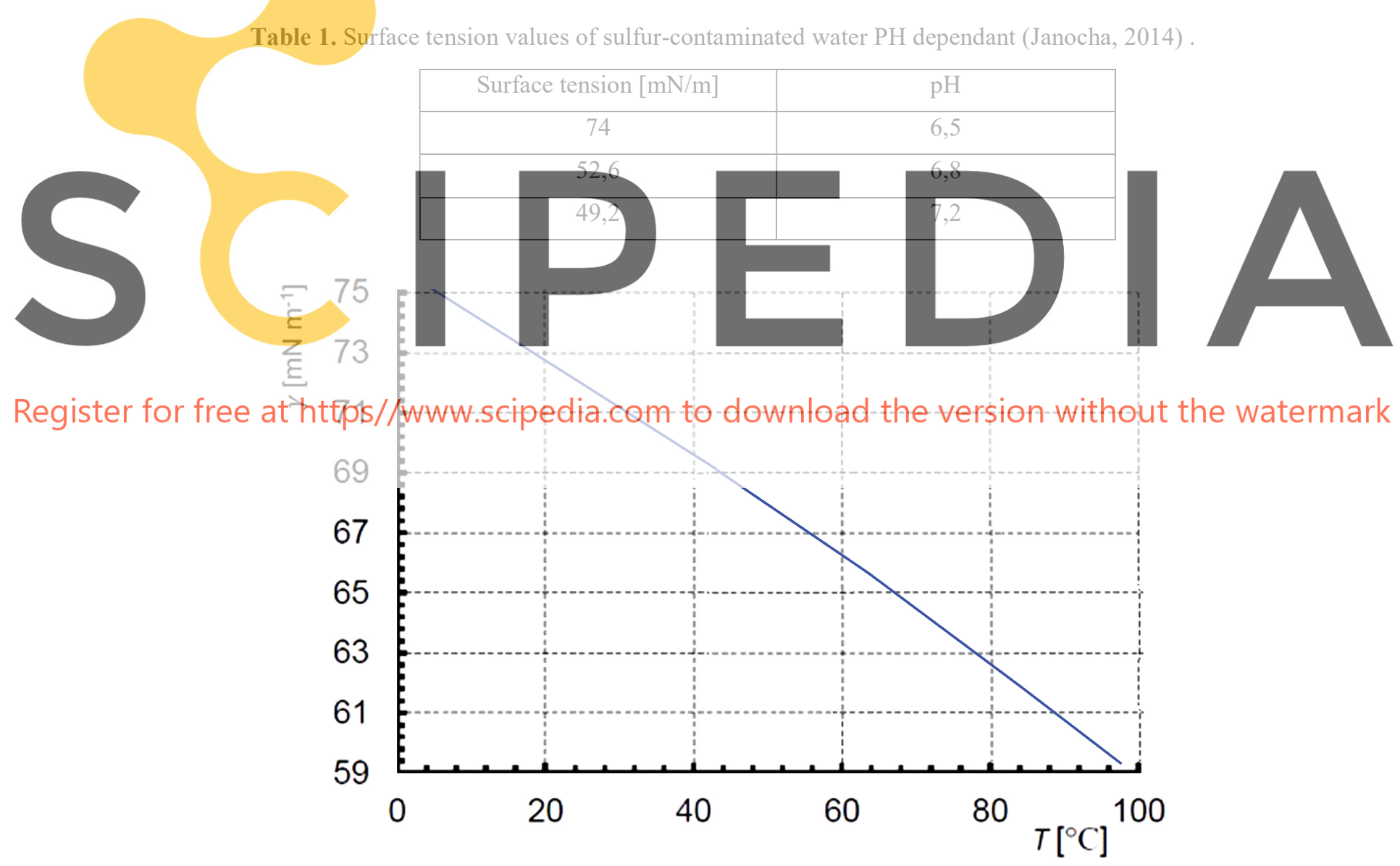

Figure 3. Surface tension of pure water as a function of temperature (at saturation pressure) (Vargaftik at al., 1983). 


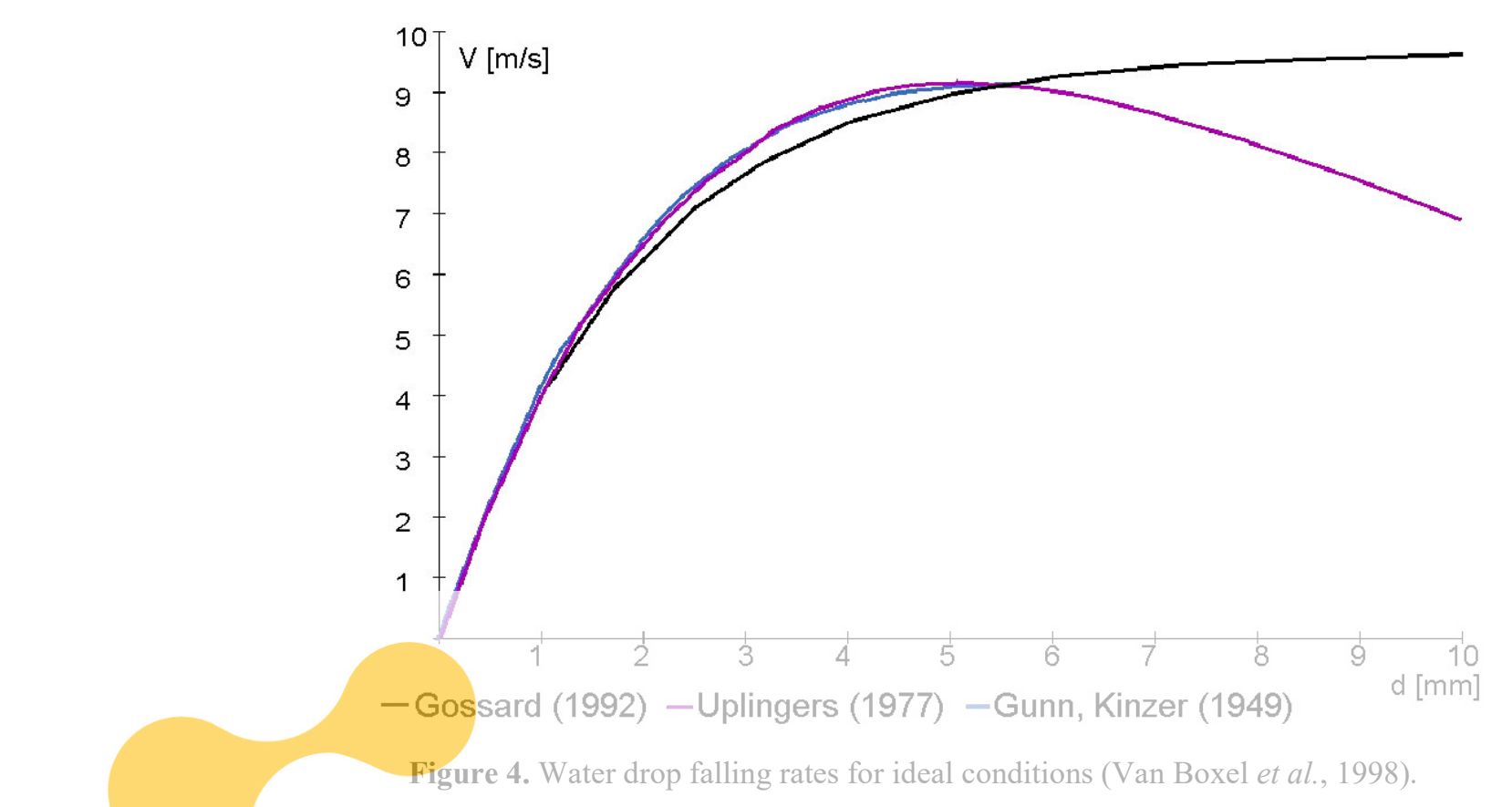

Analysis of released granules accumulation places and the impact on the destruction of these places; location of accumulation of unbound granules; phenomena occurring at places where pellets accumulate; the and roof.
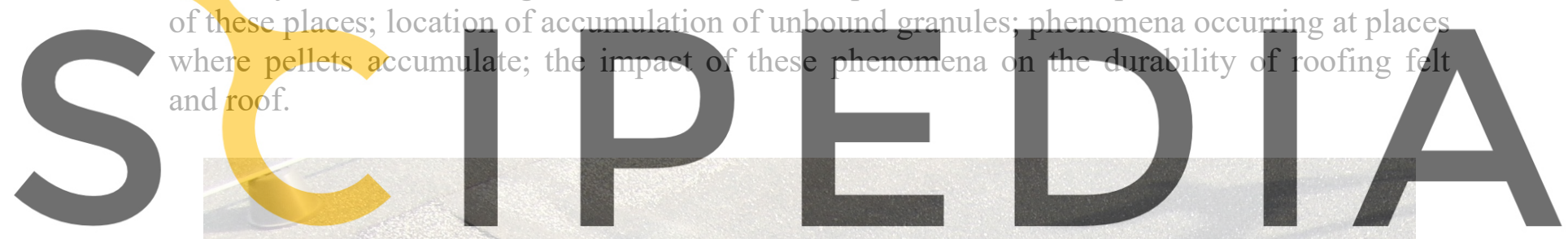

Register for free at https//www.scipedia.com to download the version without the watermark

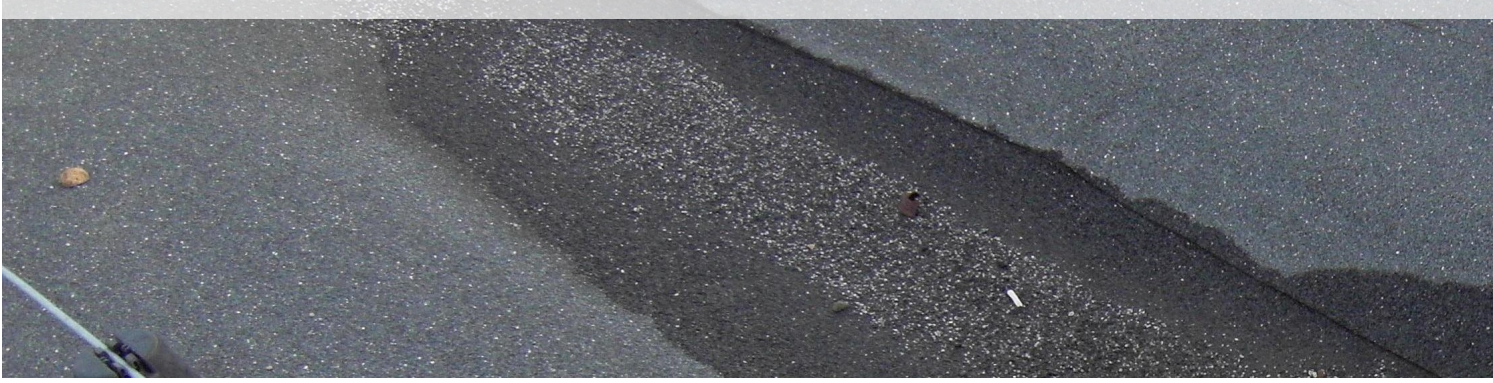

Figure 5. Accumulation of released granules (roof after one year of operation)

Analysis of the impact of granules accumulating in the gutters on gutter durability: transport for gutters - mechanical impact; transport in gutters - mechanical impact; slowing down the flow of water and prolonging the impact of chemical compounds present in the water flowing from the roof (influence of rainfall intensity on corrosion). 


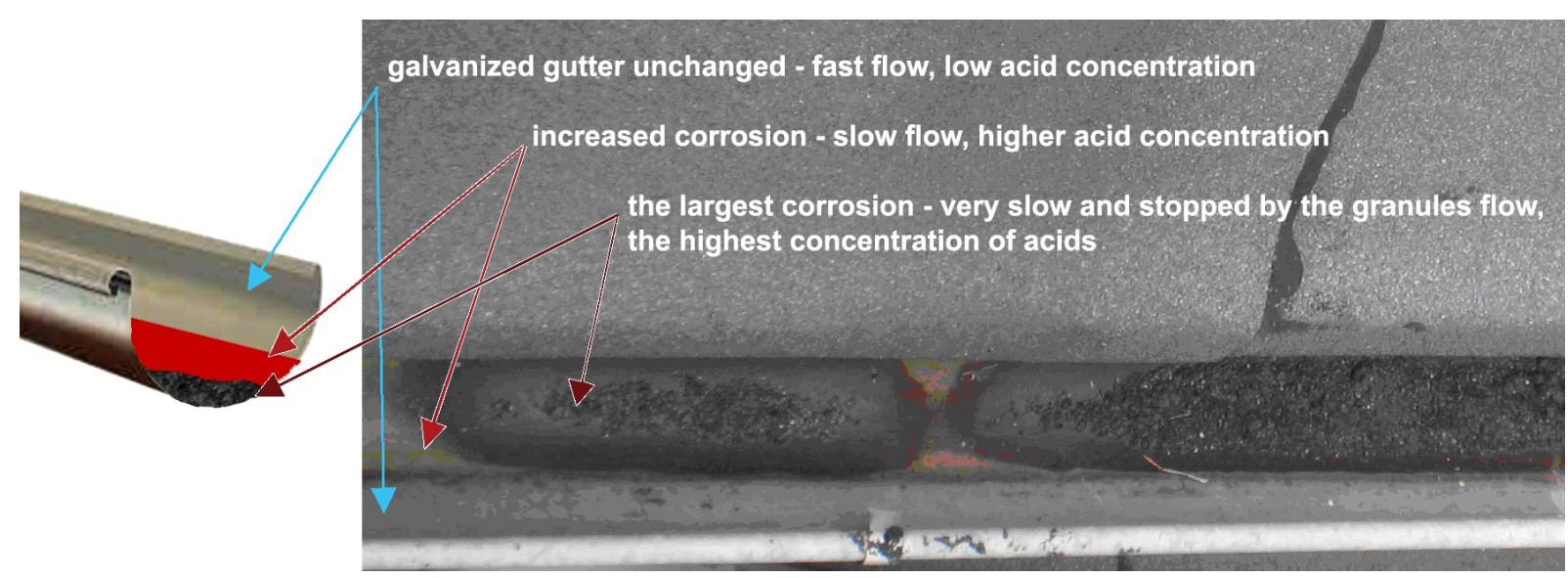

Figure 6. Accumulation of free granules in the gutter, retention of chemically polluted water and corrosion. The rust level determines the water flow rate at which the acid concentration is sufficient to cause rapid corrosion. The concentration of chemical pollution increases during low runoff from the roof surface.

Analysis of the impact of granules transported with water on the durability of downpipes: topping transport in downpipes; clogging of pipe inflows and outflows.

Analysis of the impact of hail rainfall on driving the topping into the polymer-asphalt layer

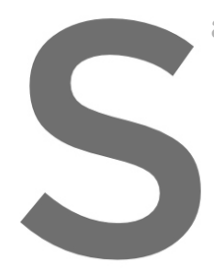
at a significantly heated
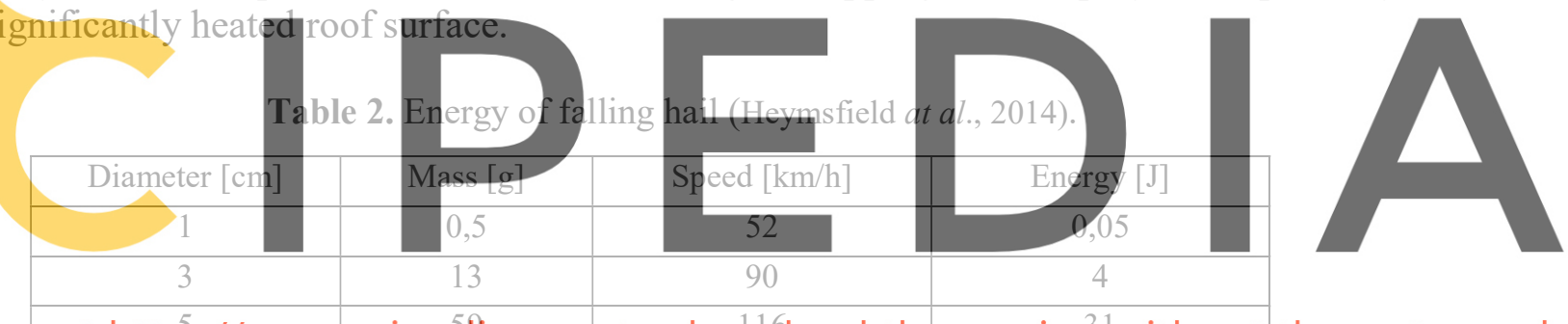

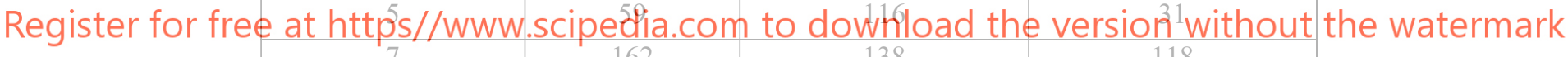

\begin{tabular}{|l|l|l|l|}
\hline 7 & 162 & 138 & 118 \\
\hline 10 & 471 & 164 & 491 \\
\hline
\end{tabular}

Effect analysis of contacts of polymer-asphalt felt with elements of different thermal expansion (flashings, batten protections ...) on defects in granules: way of contacts interact; resistance of roofing felt to contacts; increased granules defects at the contact points and consequences for exposed polymeric asphalt.

Analysis of the impact of roof loading elements (e.g. roof bases for lightning and ventilation systems) on indentation of granules in the places of contact edges at high temperatures: quality of loading elements - eccentricity for small elements, edge action and wind action for large elements; the effect of high temperatures on roofs for puncturing asphalt roofing felt with granules.

Analysis of the impact of exposing polymeric asphalt mass by tearing off the topping and releasing mainly sulfur compounds as a prolonged process: sulfur compounds as a component of polymer-asphalt mass; long-term release of sulfur compounds; the impact of sulfur compounds on roof elements (Figure 6). 
Analysis of the influence of granules on the possibility of accumulation of deposits constituting the basis enabling the growth of living organisms: topping structure that holds deposits; collecting water.

Analysis of the impact of living organisms (algae, lichen, mosses, plants) on pulling out roofing powder: colonization by living organisms; method of long-term extraction of granules (growth of mosses, lichen, plants).

Analysis of the impact of temperatures on roofs on the possibility of sinking the granules in the top layer of roofing felt and the possibility of penetration into the layer of polyester nonwoven fabric: polymer decoupling temperature for lower quality roofing paper; impact on the decomposition temperature of polymers in roofing paper resulting from the lack of obligation to carry out direct tests and to specify the composition of polymerasphalt; methods of kneading the granules (shoes, storage of renovation materials).

Analysis of the shape and size of the granules influence for possible damage to roofing felt: granules used by roofing felt producers and their most common shapes; size, thickness of topping; the possibility of causing damage.

\section{Results}

As a result of research and analysis we have determined:

The positive functions of roof granules - as the protective layer are: mechanical protection;

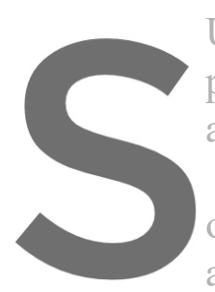
UV protection; now

protection measures architectural and decorat Negative impacts of attachment in poly and the possibility of retaining deposits and increasing the reffection of heat radiation);
"protective layer" on the roof are: uncertainty
tection losses; too high potosity of the layer
water in the layer; systematic and unavidable release of pellets during roof operation; leaching of sulfur compounds from asphalt resulting

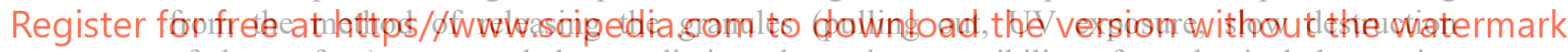
of the surface); too much heat radiation absorption; possibility of mechanical destructive impact on polymer-asphalt; making it possible to transfer the destructive effects of freezing water to polymer-asphalt (the protective layer is a tool of destruction); accumulation of released pellets in different areas of the roof increasing the amount of deposits and water retained on the roof; mechanical impact of granules transported by rain and wind on other roof elements; participation in clogging water outflows; weakening of torched joints between transverse joint of the roofing felt.

\section{Conclusions}

Elimination the negative effects of roof granules on existing roofing felt is possible by: coating with materials that reduce the porosity of the layer; covering with materials increasing the reflection of solar radiation; increasing resistance to the development of living organisms; coating with materials that reduce the release of primarily sulfur compounds. Such actions are effective but expensive and labor-intensive. 
Elimination of the negative effects of granules layer is possible by replacing it in the production process with materials characterized by: inability to accumulate in the layer wet and dry deposits; reflection of a significant part of solar radiation; limiting or eliminating the possibility of harmful chemical compounds emission from modified asphalt, above all sulfur; high adhesion to asphalt; the possibility of periodic and cheap renovation - enabling the use of cheap spray paints; enabling the effects of texture and colors for small visible roofs; gives possibility of obtain flat and smooth self-cleaning surfaces for large-area roofs. Such actions are more beneficial, cost effective and introduce the possibility of cheaper and simpler systematic renovation of roof coverings, increasing their durability.

In connection with the climate change, there is an urgent need to redefine the territorial aapplication of cover materials and their required characteristics for these areas.

The authors team is in the process of developing and patenting a new material solution for the surface layer of asphalt felt for flat roofs. The solution should, basing on existing production technology, enable the production of a new generation of roofing felt.

ORCID

Tomasz Szkuta: http://orcid.org/ 0000-0003-2089-1106

Maria Wesołowska: http://orcid.org/ 0000-0001-7914-6077

References:

Barnat-Hunek D. (2016) hydrofobizacji w ochron

Boczkaj G. (2012) Badania naftowych (in Polish).

Cullen W. C. NIST various st

Heymsfield A. J., and Giammance hailstones. Geophys. Res.
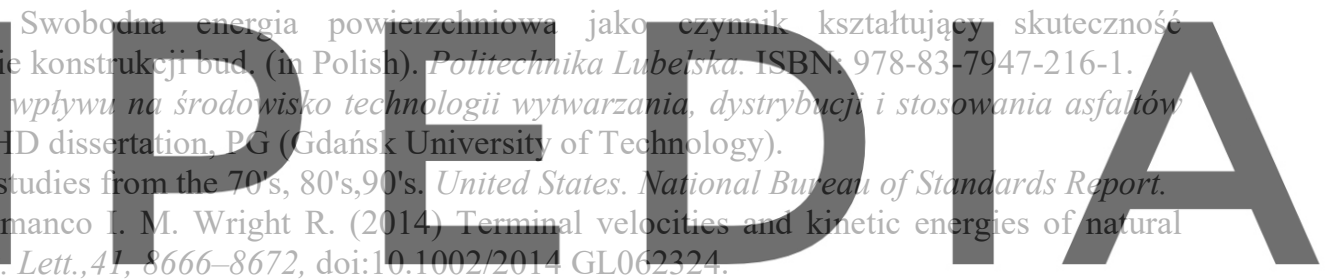

Janocha A. (2014) Zmiany napięcia powierzchniowego zasiarczonej wody złożowej na granicy z powietrzem

Kałasa J. (1988) Blodegradacja przeciwwilgociowych materiałow 1zolacyjnych (in Polish). Building Research Institute (ITB) - Quarterly no 4 (108).

Porowska D. (2005) Ocena zanieczyszczenia opadów atmosferycznych w rejonie Warszawy na tie badań regionalnych (in Polish). Przeglad Geologiczny 53, p. 1060-1061.

Stefańczyk B. and Mieczkowski P. (2008) Wpływ czynników fizyczno-chemicznych na kształtowanie trwałych i skutecznych hydroizolacji papowych (in Polish). Materiaty Budowlane 430/08, p. 12-13.

Szkuta T. and Wesołowska M. (2019) Skutki zjawisk fizycznych na dachach płaskich. Część I Nieprawidłowości, analiza stanu (in Polish). Przegląd Budowlany 7-8/19 p. 103-105. ISSN0033-2038, Indeks 37067.

Trzaska E. (2011) Adhezja asfaltu do kruszywa (in Polish). Nafta-Gaz 6/11, p. 423 - 427.

Vargaftik N.B., Volkov B.N. and Voljak L.D. (1983) International tables of the surface tension of water. J. Phys. Chem. Ref. Data 12 p. 817-820.

Van Boxel J. (1998). Numerical model for the fall speed of raindrops in a rainfall simulator. ICE Special Report, 1998/1, p. $77-85$

Żelazny M. (2005) Wpływ czasu trwania opadu atmosferycznego (mokrego) na średnią dynamikę zmian stężeń jonów w pojedynczym opadzie w zasięgu oddziaływania dużych ośrodków miejsko-przemysłowych Łazy k. Bochni (in Polish). v. 53 n. 11, Indeks 370908, ISSN-0033-2151. 